\title{
Evaluation of specific biochemical indicators of Helicobacter pylori-associated gastric cancer in Egypt
}

\author{
M.M. Anwar, ${ }^{1}$ A.I. Youssef, ${ }^{2}$ M.I. Sheta, ${ }^{3}$ A. Zaki, ${ }^{4}$ N.R. Bernaba ${ }^{2}$ and M.A. El-Toukhi ${ }^{2}$
}

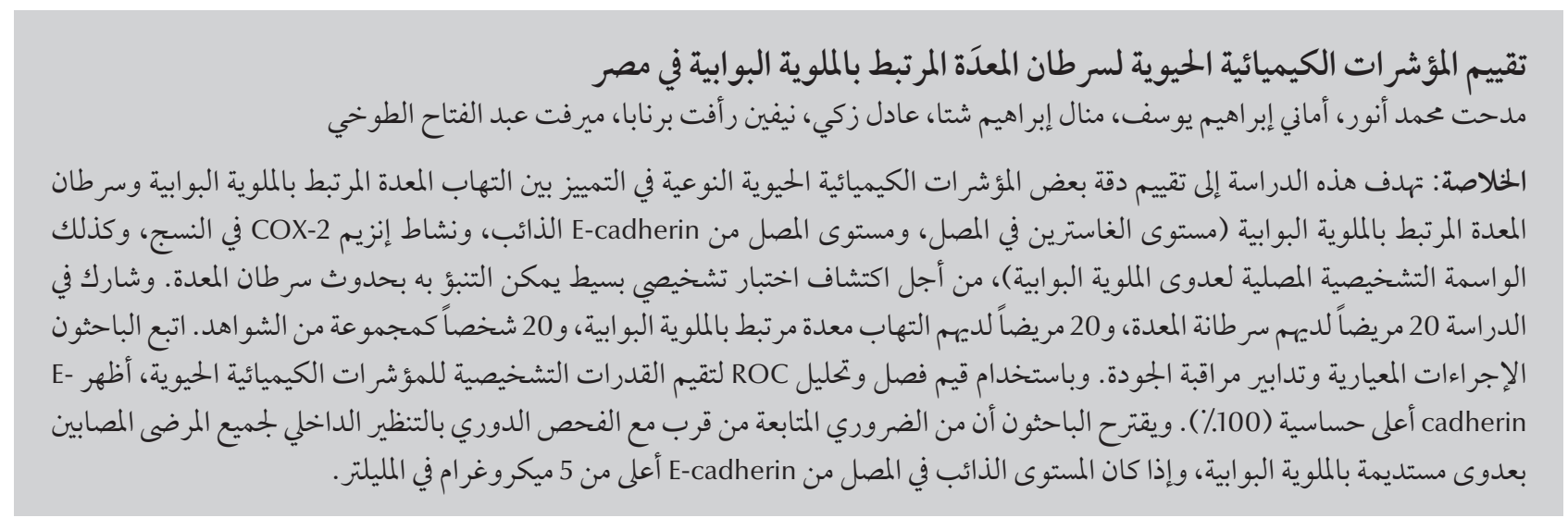

ABSTRACT The aim of the study was to assess the accuracy of some specific biochemical indicators in discriminating between Helicobacter pylori-associated gastritis and H. pylori-associated stomach cancer (serum gastrin level, serum soluble E-cadherin and tissue COX-2 activity, as well as serodiagnostic markers for $H$. pylori infection) in order to find a simple diagnostic test that can reasonably predict the development of gastric cancer. The study participants comprised 20 patients with gastric carcinoma, 20 patients with positive $H$. pyloriassociated gastritis and 20 individuals as the control group. Standard procedures and quality control measures were followed. Using cut-off values and ROC analysis to assess the diagnostic abilities of the biochemical indicators, E-cadherin showed the highest sensitivity (100\%). We suggest that close follow-up together with periodic endoscopic examination for all patients with persistent $H$. pylori infection and serum soluble E-cadherin level above $5 \mu \mathrm{g} / \mathrm{mL}$ is essential.

\section{Évaluation des indicateurs biologiques spécifiques du cancer de l'estomac associé à Helicobacterpylori en Égypte}

RÉSUMÉ La présente étude visait à évaluer l'exactitude de certains indicateurs biologiques spécifiques (gastrinémie, concentration sérique de la E-cadhérine soluble, activité tissulaire de la cyclo-oxygénase 2, et marqueurs sérologiques d'une infection à Helicobacter pylori) permettant de différencier une gastrite associée à H. pylori d'un cancer de l'estomac associé à cette bactérie, afin de déterminer un test diagnostique simple capable de prédire raisonnablement l'apparition d'un cancer de l'estomac. L'étude portait sur 20 patients atteints d'un carcinome gastrique, 20 patients souffrant d'une gastrite à H. pylori et 20 personnes en tant que groupe témoin. Des procédures normalisées ont été suivies et des mesures de contrôle de la qualité ont été effectuées. Après l'utilisation de valeurs seuils et d'une analyse de la fonction d'efficacité du récepteur pour évaluer les qualités diagnostiques des indicateurs biologiques, la E-cadhérine a montré la sensibilité la plus élevée (100\%). Nous suggérons qu'un suivi attentif et un examen endoscopique régulier sont essentiels pour tous les patients atteints d'une infection à $H$. pylori persistante et présentant une concentration sérique de la E-cadhérine soluble supérieure à $5 \mu \mathrm{g} / \mathrm{ml}$.

${ }^{7}$ Department of Experimental and Clinical Surgery; ${ }^{2}$ Department of Applied Medical Chemistry; ${ }^{3}$ Department of Pathology; ${ }^{4}$ Department of Medical Informatics and Medical Statistics, Medical Research Institute, University of Alexandria, Alexandria, Egypt (Correspondence to M.M. Anwar:medhatanwar@gmail.com).

Received: 01/08/10; accepted: 22/11/10 


\section{Introduction}

Gastric cancer is the fourth commonest malignant disorder and the second commonest cause of cancer-related death worldwide [1]. It represents $1.64 \%$ of all cancers in Egypt, according to the National Cancer Institute registry and the median age is 55 years with male predominance [2]. Several studies have linked Helicobacter pylori and gastric cancer. The etiopathogenetic cascade of the infection leads to various errors in the genome of dividing gastric epithelial cells, which leads to abnormal differentiation of cells [3]. In addition, chronic inflammation associated with the infection leads to damage in proteins, the production of reactive oxygen species and deficient repair of replication errors of DNA. All increase the risk of gastric cancer $[3,4]$.

Among the pathogenic virulence factors in $H$. pylori infection is CagA protein, which is produced by most strains into the gastric cells and phosphorylated by the host kinases, resulting in morphological changes in the epithelial cells [5]. CagA positive H. pylori infection up-regulates the expression of the enzyme cyclo-oxygenase-2 (COX2 ), which converts arachidonic acid to prostaglandin E2 [6]. The angiogenicenhancing role of COX-2 facilitates the process of invasion and metastasis through decreasing the expression of the adhesion molecule E-cadherin. E-cadherin is expressed by epithelial cells and is responsible for homotypic cell-cell adhesion. Degradation of tissue E-cadherin produces serum soluble E-cadherin, which is greatly elevated in inflammatory conditions by mediators, or in cancerous disease due to the overexpression of proteases [7]. As the initial stage of $H$. pylori infection is an acute gastritis, so the acid response of the stomach is affected, and gastrinaemia is induced; this is associated with the occurrence of gastric adenocarcinoma [8].

Researchers have documented that H. pylori eradication therapy attenuates the endoscopic and histological lesions [9]. Besides, many studies have consistently reported that $H$. pylori eradication can lead to a regression of acute gastritis and intestinal metaplasia, and that such intervention could reduce the risk for adenocarcinoma of the distal stomach $[10,11]$

When clinically manifested, gastric cancer has an extremely poor prognosis since the 5-year survival rate using currently available treatments, surgery and radio-chemotherapy, is less than $20 \%$ [12]. Therefore a potential benefit could be expected if we had a feasible diagnostic test for follow-up of patients with $H$. pylori gastritis and were able to predict the risk of development of stomach cancer.

In this study, we aimed to assess the accuracy of specific biochemical indicators to discriminate between $H$. pylori-associated gastritis and H. pyloriassociated stomach cancer.

\section{Methods}

\section{Patients and samples}

Twenty consecutive adult patients attending the Endoscopy Unit, Department of Surgery, Medical Research Institute in the University of Alexandria during the period January 2008-June 2009 and proven by endoscopic, pathological and radiological examinations to have an operable stomach cancer were involved in the study. Sample size was restricted owing to limited time resources. None of the patients had received chemotherapy before surgical operation. For each patient with stomach cancer, the next adult patient with endoscopic diagnosis of $H$. pyloriassociated gastritis, free of any malignant changes, was recruited in the study. In addition, for each patient with stomach cancer, the next age-matched (within 5 years) individual presenting with epigastric pain which proved to have normal endoscopic findings and who was negative for H. pylori was included in the study as part of the control group. All individuals in the study sample were subjected to routine history and clinical examination, followed by an upper gastrointestinal endoscopic examination using a long forward viewing instrument (Fuji, EG 250D video). The stomach was completely examined for the presence or absence of any gross pathological sign.

All 60 contributors were subjected to multiple endoscopic gastric mucosal tissue biopsies. These were examined pathologically to confirm the presence or absence of gastritis and/or malignancy and for biochemical determination of tissue COX-2 activity using COX Activity Assay Kit (Cayman Chemical Company, Cat. No.760151). The COX activity assay utilizes the peroxidase component of cyclo-oxygenases. Peroxidase activity was assayed colorimetrically by monitoring the appearance of oxidized N,N,N',N'-tetramethyl-pphenylenediamine at $590 \mathrm{~nm}$ [13]. The assay included COX-1 and COX-2 specific inhibitors in order to distinguish between the 2 isozymes.

Serological examination was carried out to estimate serum gastrin level and serum soluble E-cadherin level besides serodiagnostic markers for $H$. pylori infection, $H$. pylori antigen, $H$. pylori CagA antibody and H. pylori IgG antibody.

Serum gastrin level was measured using Gastrin-17 ELISA kit (Biohit Plc, Cat. No.601035). The G-17 ELISA is based on a sandwich enzyme immunoassay technique with a G-17 specific capture antibody adsorbed to a microwell plate and a detection antibody labelled with horseradish peroxidase [14]. Serum soluble E-cadherin was measured using the Human E-cadherin EIA kit (Takara Bio Inc., Code No. MK117). The human E-cadherin EIA kit is a solid phase EIA based on a sandwich method that utilizes 2 mouse monoclonal anti-human E-cadherin antibodies to detect soluble E-cadherin in a 2-step procedure [15]. 
H. pylori Ag ELISA (ABC Diagnostics, New Damietta) was used to determine serum $H$. pylori antigen level; determination of serum $H$. $p y$ lori CagA antibodies was done using ELISA H. pylori CagA IgG Quantitative (RightChoice Diagnostics, code REP 1004), while H. pylori IgG antibody was measured using H. pylori IgG Quantitative ELISA Kit (MP Biomedicals, LLC, Cat. No. 07BC1052). All steps were carried out according to the manufacturer's instructions [16-18].

\section{Quality control}

All the steps for the blood and tissue sampling were done under the authors' supervision and followed standard procedures. All tests were performed in duplicate. All individuals agreed to participate after the aims of the study were explained to them and gave informed consent.

The study was approved by the institutional ethical committee of the Medical Research Institute, Alexandria University.

\section{Histopathological examination}

After the surgical management for patients with stomach cancer was done, the gastric specimens were fixed into $10 \%$ formalin and routinely processed for pathological examination. Paraffin wax-embedded sections were cut into 3-5 $\mu$ thick serial sections and stained with haematoxylin and eosin. Gastric cancer was classified according to Lauren's classification [19], which divides gastric adenocarcinoma into intestinal, diffuse and mixed types.

\section{Statistical analysis}

Data analysis was conducted using SPSS, version 17.0. Descriptive statistics were presented as mean [standard deviation (SD)] for quantitative data and frequency for qualitative data. Analysis of variance (ANOVA) was used to test the significance of the mean differences in serum gastrin level, serum soluble
E-cadherin, CagA antibody, and tissue COX-2 activity between the 3 different groups. Unpaired $t$-test with Bonferroni correction for multiple comparisons was used to test the significance of differences in mean $H$. pylori antigen, $H$. pylori IgG antibody and H. pylori CagA antibody. Due to the small sample size in the subgroups of stomach cancer patients, a non-parametric test (MannWhitney) was used. $P$-value $<0.05$ was considered statistically significant.

The ROC analysis was used to assess the diagnostic abilities of the biochemical indicators in the discrimination between patients with $H$. pylori gastritis and those with stomach cancer. The cut-off point which optimizes the accuracy of the diagnostic test was defined as the point which maximizes the value of the Youden index (sensitivity + specificity-1).

\section{Results}

Patients were divided into 3 groups, each with 20 patients, group I (control group), group II (patients with $H$. pylori-associated gastritis), and group III (patients with stomach cancer). The distribution of sex and age of all the participants is shown in Table 1.

\section{Endoscopic, surgical and histopathological findings}

In group II patients, pathological examination of the gastric tissue biopsies showed 5 cases with superficial gastritis, 4 cases with atrophic gastritis, 2 cases with gastroduodenitis, and 9 cases with benign gastric ulcer.

In group III patients, all endoscopic malignant changes were localized in the antrum and prepyloric region except in 2 patients where cancer was localized in the body of the stomach as malignant ulcers and polypoidal mass. After confirmation of the malignant nature of the disease by pathological examination of the endoscopic biopsies, 14/20 (70\%) underwent subtotal gastrectomy and $6 / 20(30 \%)$ underwent total gastrectomy. After surgery, the pathological findings were as follows: 10 cases (50\%) were of intestinal type adenocarcinoma, 7 (35\%) were diffuse type adenocarcinoma and 3 (15\%) were of the mixed type. Table 2 shows the histopathological type of operated gastric cancer patients. None of the gastric cancer patients included in this study was free from H. pylori infection.

\section{Biochemical indicators}

All the differences in mean serum gastrin level, tissue COX-2 activity, serum E-cadherin and CagA antibody between the study groups were highly significant $(P<0.01)$. Patients with stomach cancer had the highest in serum gastrin levels, tissue COX-2 activity and serum E-cadherin followed by the group with positive H. pylori-associated gastritis (Table 3). For CagA antibody,

\begin{tabular}{|c|c|c|c|c|c|c|}
\hline \multirow[t]{2}{*}{ Characteristic } & \multicolumn{2}{|c|}{$\begin{array}{l}\text { Group I } \\
(n=20)\end{array}$} & \multicolumn{2}{|c|}{$\begin{array}{l}\text { Group II } \\
(n=20)\end{array}$} & \multicolumn{2}{|c|}{$\begin{array}{c}\text { Group III } \\
(n=20)\end{array}$} \\
\hline & No. & $\%$ & No. & $\%$ & No. & $\%$ \\
\hline \multicolumn{7}{|l|}{ Sex } \\
\hline Male & 9 & 45 & 14 & 70 & 13 & 65 \\
\hline Female & 11 & 55 & 6 & 30 & 7 & 35 \\
\hline Mean (SD) age (years) & \multicolumn{2}{|c|}{$48.5(2.3)$} & \multicolumn{2}{|c|}{$49.3(1.6)$} & \multicolumn{2}{|c|}{$46.9(2.0)$} \\
\hline
\end{tabular}

Group I = control group; group II = patients with Helicobacter pylori-associated gastritis; group III = patients with stomach cancer.

The chi-squared test was used for difference in of distribution among the study groups and ANOVA for difference in mean age, $P<0.05$.

$S D=$ standard deviation. 


\begin{tabular}{lccccc}
\hline Table 2 Histopathology and type of surgery for the $\mathbf{2 0}$ patients with stomach cancer \\
\hline Type of gastrectomy & $\begin{array}{c}\text { Intestinal } \\
(\boldsymbol{n}=\mathbf{1 0})\end{array}$ & $\begin{array}{c}\text { Histopathological adenocarcinoma type } \\
\text { Diffuse } \\
(\boldsymbol{n}=\mathbf{7})\end{array}$ & $\begin{array}{c}\text { Mixed } \\
(\boldsymbol{n}=3)\end{array}$ & $\begin{array}{c}\text { Total } \\
(\boldsymbol{n}=\mathbf{2 0})\end{array}$ \\
Subtotal & No. & No. & No. & No. & $\%$ \\
Total & 9 & 2 & 3 & 14 & 70 \\
\hline
\end{tabular}

\begin{tabular}{|c|c|c|c|c|}
\hline Parameter & $\begin{array}{l}\text { Group Ia } \\
(n=20)\end{array}$ & $\begin{array}{l}\text { Group II } \\
(n=20)\end{array}$ & $\begin{array}{c}\text { Group III } \\
(n=20)\end{array}$ & $P$-value ${ }^{\mathrm{t}}$ \\
\hline & Mean (SD) & Mean (SD) & Mean (SD) & \\
\hline Serum gastrin (pmol/L) & $5.3(1.4)$ & $16.6(3.8)$ & $30.3(5.9)$ & $<0.01$ \\
\hline COX-2 activity $(\mathrm{U} / \mathrm{mL})$ & $414.9(87.4)$ & $632.8(122.7)$ & $1106.4(298.5)$ & $<0.01$ \\
\hline Serum E-cadherin $(\mu \mathrm{g} / \mathrm{mL})$ & $1.9(0.3)$ & $4.3(0.7)$ & $6.4(1.2)$ & $<0.01$ \\
\hline Serum CagA-Ab (Uarb/mL) & $2.2(1.0)$ & $64.4(14.3)$ & $52.4(11.0)$ & $<0.01$ \\
\hline
\end{tabular}

${ }^{a}$ All between-group comparisons were statistically significant $(P<0.05)$.

${ }^{b}$ ANOVA test.

Group I = control group; group II = patients with H. pylori-associated gastritis; group III = patients with stomach cancer . $S D=$ standard deviation.

the group with H. pylori gastritis showed the highest level.

Considering the levels of the studied biochemical indicators in the 3 pathologic subtypes of gastric cancer patients, serum gastrin and tissue COX-2 activity were significantly higher in the intestinal subtype compared with the diffuse type $(P<0.05)$, while serum E-cadherin was significantly higher in the diffuse type (Table 4). Intermediate levels were seen in the mixed type.

ROC analysis was adopted to identify the cut off points for serum gastrin level, tissue COX-2 activity, and serum E-cadherin, which maximizes the overall accuracy of these biochemical indicators in the discrimination between individuals with $H$. pylori infection with or without stomach cancer. The corresponding sensitivity and specificity of each cut-off point was relatively high, ranging from $80 \%$ to $100 \%$. E-cadherin had the greatest sensitivity (100\%) in detecting stomach cancer (Table 5).

Serum levels of $H$. pylori antigen, CagA and IgG antibodies were significantly greater in groups II and III than group I $(P<0.05)$ (Table 6$)$. Comparing group II with group III, these parameters were significantly lower in group III $(P<0.05)$.

\section{Discussion}

In our study all patients with stomach cancer were positive for $H$. pylori. The significantly higher levels in $\mathrm{H}$. pylori antigen and H. pylori IgG and CagA antibodies when comparing each of the infected groups with the control group explain the evidence that CagA positive strains of H. pylori are considered virulent and have a highly pathogenic effect on gastric mucosa and that they have been related to ulcers and greatly increase the risk of gastric cancer $[20,21]$. In our work, the levels of H. pylori CagA antibodies in the gastric cancer group were about 19\% lower than those in

\begin{tabular}{|c|c|c|c|}
\hline \multirow[t]{3}{*}{ Parameter } & \multicolumn{3}{|c|}{ Type of gastric cancer } \\
\hline & $\begin{array}{c}\text { Diffuse } \\
(n=7)\end{array}$ & $\begin{array}{c}\text { Intestinal } \\
(n=10)\end{array}$ & $\begin{array}{l}\text { Mixed } \\
(n=3)\end{array}$ \\
\hline & Mean (SD) & Mean (SD) & Mean (SD) \\
\hline Serum gastrin $(\mathrm{pmol} / \mathrm{L})$ & $24.0(1.3)$ & $33.8(1.2)^{*}$ & $33.7(1.5)$ \\
\hline Tissue COX-2 activity $(\mathrm{U} / \mathrm{mL})$ & $880(87)$ & $1297(440)^{*}$ & 999 (271) \\
\hline Serum E-cadherin $(\mu \mathrm{g} / \mathrm{mL})$ & $7.80(0.30)$ & $5.50(0.11)^{*}$ & $6.45(0.01)$ \\
\hline
\end{tabular}

Mann-Whitney test was used for comparison between diffuse and intestinal type. No statistical tests were applied to the mixed type owing to the very small sample size. *Significant at $P<0.05$.

$S D=$ standard deviation. 


\begin{tabular}{|c|c|c|c|}
\hline Parameter & Cut-off & Sensitivity (\%) & Specificity (\%) \\
\hline E-cadherin $(\mu \mathrm{g} / \mathrm{mL})$ & 5 & 100 & 80 \\
\hline $\mathrm{COX}-2(\mathrm{U} / \mathrm{mL})$ & 755 & 85 & 90 \\
\hline Gastrin (pmol/L) & 26 & 80 & 100 \\
\hline
\end{tabular}

the H. pylori-associated gastritis group, while, H. pylori $\operatorname{IgG}$ antibodies were about $26 \%$ lower. The significant difference in these parameters was similar to the results obtained by Meimarakis et al., who found that there was a spontaneous decline in $H$. pylori antibody as gastric carcinogenesis proceeds, and that CagA antibody persists longer in serum that H. pylori IgA antibody [22]. This also may be explained by the idea that in patients with severe atrophic gastritis, H. pylori infection may be difficult to demonstrate because the bacteria disappear spontaneously and even $H$. pylori antibody titres eventually decline to normal [23].

The availability of a simple diagnostic test which can reasonably predict the development of stomach cancer could be of high practical importance. The most impressive finding in this study was the striking differences in the levels of serum gastrin, COX-2 activity, serum soluble E-cadherin and CagA antibody in patients with $H$. pylori gastritis compared with healthy control individuals. A further striking increase in these biochemical parameters is found in individuals with $H$. pylori-associated gastric cancer. The reasons for that need some explanation.

Gastrin is involved in the tumorogenesis in the gastrointestinal tract [24], and plays a key role in the initiation and the progression of cancer through the adenoma-carcinoma sequence in the stomach [25]. Recent studies showed a significantly higher level in H. pylori-infected patients than the seronegative ones [26], which is secondary to H. pylori colonization of the gastric body and fundus, resulting in decreased acid secretion and thus lowering the inhibitory feedback on gastrin release [27]. Also, H. pylori infection plays a significant role in the stimulation of $\mathrm{G}$ cells [28]. This explains the progressively significantly higher serum gastrin levels in groups II and III.

The statistically significant elevation of serum gastrin level in group III, especially in the intestinal and mixed forms, compared with patients in group II led us to believe like other researchers that gastrin could originate from extra G-cell sources, including cancer cells themselves [2]. Also, a strong positive correlation between serum gastrin and each of H. pylori $\operatorname{IgG}$ and CagA antibodies confirms that hypergastrinaemia and
H. pylori expressing CagA might contribute to the transformation of normal epithelial cells into cancer cells in the $H$. pylori-infected stomach [2]. Väänänen et al. determined this blood test panel, together with the assay of $H$. pylori antibodies, as a good non-endoscopic diagnostic and screening tool for gastric cancer [29].

The roles of H. pylori infection and gastrin have been reported to stimulate and induce overexpression of COX-2 [30]; this explains the increase in tissue COX-2 activity in the cancer group being H. pylori positive compared to group II. This increase may inhibit apoptosis and increase the invasiveness of malignant cells [31]. The highest activity for COX-2 was found in patients with the intestinal subtype of stomach cancer and this finding is in agreement with previous studies which revealed that COX-2 expression may be associated with the carcinogenesis of the intestinal type of gastric cancer and, speculatively, inhibition of COX-2 might have preventative effects on the intestinal type of gastric cancer. Also, in tumours of mixed type, COX-2 is increased in the intestinal component compared to the diffuse one [32].

Conditions with rapid cell turnover or inflammation lead to an increase in serum level of E-cadherin [7]. Perturbation in the expression or function of the transmembrane glycoprotein leading to an increase in permeability mediated by the reduction in cell adhesion might allow H. pylori antigens to reach the gastric lamina propria with resultant

\begin{tabular}{|c|c|c|c|c|}
\hline \multirow[t]{2}{*}{ Parameter } & $\begin{array}{l}\text { Group } \mathrm{I}^{\mathrm{a}} \\
(\boldsymbol{n}=\mathbf{2 0})\end{array}$ & $\begin{array}{c}\text { Group II }^{\mathrm{a}} \\
(\boldsymbol{n}=\mathbf{2 0})\end{array}$ & $\begin{array}{c}\text { Group III' } \\
(n=20)\end{array}$ & $P$-value ${ }^{\text {b }}$ \\
\hline & Mean (SD) & Mean (SD) & Mean (SD) & \\
\hline H. pylori antigen & $0.20(0.01)$ & $1.10(0.04)$ & $0.71(0.03)$ & $<0.05$ \\
\hline H. pylori CagA-Ab (Uarb/mL) & $2.2(0.2)$ & $64.4(3.2)$ & $52.3(2.4)$ & $<0.05$ \\
\hline H. pylori lgG-Ab (U/mL) & $8.8(0.5)$ & $58.9(1.97)$ & $43.6(1.4)$ & $<0.05$ \\
\hline
\end{tabular}

${ }^{a}$ All between-group comparisons were significant $(P<0.05)$ using Bonferroni correction.

${ }^{b}$ ANOVA test.

Group I = control group; group II = patients with H. pylori-associated gastritis; group III = patients with stomach cancer . $S D=$ standard deviation . 
tissue damage [33]. In our work, the significant elevation of serum soluble E-cadherin in the cancer group is in agreement with previous work which showed that serum E-cadherin is found in the circulation of normal individuals, but is particularly elevated in patients with gastric carcinoma [34]. Generally, tissue E-cadherin is strongly expressed in well differentiated cancers, but is absent, or markedly reduced in undifferentiated cancers [35], this decrease was mainly observed in diffuse type of gastric cancer and less in intestinal type [36]. These results are supported by our own since we found a significant elevation in serum soluble E-cadherin in the diffuse type of group III compared with the intestinal type $(5.5 \mu \mathrm{g} / \mathrm{mL})$. The elevated level could be an indicator for poor prognosis, metastases and decreased survival [7].

The ROC curve analysis demonstrated that tissue COX-2 activity, serum gastrin and serum soluble E-cadherin have a very important diagnostic possibility for discrimination between people with $H$. pylori-associated gastritis and those with $H$. pylori-associated stomach cancer. The high accuracy of these parameters in prediction of stomach cancer, as shown by a greater area under ROC curve, raises the possibility of their potential benefit as a follow-up test in individuals with $H$. pylori positive gastritis. As E-cadherin showed the highest sensitivity $(100 \%)$ in discriminating between H. pylori gastritis and stomach cancer, we suggest close follow-up together with endoscopic examination for all patients with previous history of H. pylori-associated gastritis and serum E-cadherin levels above $5 \mu \mathrm{g} / \mathrm{mL}$.

Although our findings suggest a potential benefit for measuring Ecadherin in the serum of patients with gastritis, we would need to conduct a larger clinical trial that would extend to include early stomach cancer as well as advanced cancer together with proper staging of the disease in order to obtain a level of confidence that would lead to a change in current clinical practices and outcomes. With a larger trial, we would be able to make more definitive statements regarding the importance of these biochemical parameters and the proper timing for measurement, especially in those patients positive for $H$. pylori. Further research is needed to help planning the follow-up strategy using these biochemical indicators.

\section{Acknowledgements}

The authors thank Professor El-Sayed Ibrahim Awad, Professor of Surgery, Medical Research Institute, Alexandria University, for his advice and valuable suggestion throughout the work.

\section{References}

1. Kamangar F, Dores GM, Anderson WF. Patterns of cancer incidence, mortality, and prevalence across five continents: defining priorities to reduce cancer disparities in different geographic regions of the world. Journal of Clinical Oncology, 2006, 24(14):2137-2150.

2. El-Bolkainy N. Topographic pathology of cancer. Cairo, Egypt, Rhone Poulenc Rorer, 2005

3. Vauhkonen M, Vauhkonen H, Sipponen P. Pathology and molecular biology of gastric cancer. Best Practice \& Research Clinical Gastroenterology, 2006, 20(4):651-674.

4. Kim J et al. Helicobacter pylori impairs DNA mismatch repair in gastric epithelial cells. Gastroenterology 2002, 123(2):542553.

5. Huang JQ et al. Meta-analysis of the relationship between cagA seropositivity and gastric cancer. Gastroenterology, 2003 125(6):1636-1644.

6. Guo XL et al. Association of cyclooxygenase-2 expression with $\mathrm{Hp}$-cagA infection in gastric cancer. World Journal of Gastroenterology, 2003, 9(2):246-249.

7. Chan $\mathrm{AO}$ et al. Soluble E-cadherin is a valid prognostic marker in gastric carcinoma. Gut, 2001, 48(6):808-811.

8. Konturek PC et al. Cancerogenesis in Helicobacter pylori infected stomach-role of growth factors, apoptosis and cyclooxygenases. Medical Science Monitor, 2001, 7(5):10921107.

9. Ito $\mathrm{M}$ et al. Causal role of Helicobacter pylori infection and eradication therapy in gastric carcinogenesis. World Journal of Gastroenterology, 2006, 12:10-16.

10. Mera R et al. Long term follow up of patients treated for Helicobacter pylori infection. Gut, 2005, 54:1536-1540.
11. Leung WK et al. Factors predicting progression of gastric intestinal metaplasia: results of a randomised trial on Helicobacter pylori eradication. Gut, 2004, 53:1244-1249.

12. Egan BJ, O'Morain CA. A historical perspective of Helicobacter gastroduodenitis and its complications. Best Practice \& Research Clinical Gastroenterology, 2007, 21(2):335-346.

13. Kulmacz RJ, Lands WE. Requirements for hydroperoxide by the cyclooxygenase and peroxidase activities of prostaglandin H synthase. Prostaglandins, 1983, 25:531-540.

14. Goetze JP, Rehfeld JF. Impact of assay epitope specificity in gastrinoma diagnosis. Clinical Chemistry, 2003, 49(2):333-334.

15. Katayama $\mathrm{M}$ et al. Soluble E-cadherin fragments increased in circulation of cancer patients. British Journal of Cancer, 1994, 69(3):580-585.

16. Attallah AM et al. Use of a novel enzyme immunoassay based on detection of circulating antigen in serum for diagnosis of Helicobacter pylori infection. Clinical and Diagnostic Laboratory Immunology, 2004, 11(4):775-779.

17. Gerstenecker B et al. Serodiagnosis of Helicobacter pylori infections with an enzyme immunoassay using the chromatographically purified 120 kilodalton protein. European Journal of Clinical Microbiology \& Infectious Diseases, 1992, 11(7):595-601.

18. Perez-Perez GI et al. Seroprevalence of Helicobacter pylori infection in couples. Journal of Clinical Microbiology, 1991, 29(3):642-644.

19. Lauren P. The two histological main types of gastric carcinoma: diffuse and so-called intestinal-type carcinoma. An attempt at a histo-clinical classification. Acta Pathologica et Microbiologica Scandinavica, 1965, 64:31-49. 
20. Konturek SJ et al. Helicobacter pylori and CagA status, serum gastrin, interleukin-8 and gastric acid secretion in gastric cancer. Scandinavian Journal of Gastroenterology, 2002, 37(8):891-898

21. Aviles-Jimenez F et al. Evolution of the Helicobacter pylori vacuolating cytotoxin in a human stomach. Journal of Bacteriology, 2004, 186(15):5182-5185.

22. Meimarakis $\mathrm{G}$ et al. Helicobacter pylori as a prognostic indicator after curative resection of gastric carcinoma: a prospective study. Lancet Oncology, 2006, 7(3):211-222.

23. Kokkola A et al. Spontaneous disappearance of Helicobacter pylori antibodies in patients with advanced atrophic corpus gastritis. Acta Pathologica, Microbiologica. et Immunologica Scandinavica, 2003, 111(6):619-624.

24. Song DH et al. Gastrin-induced gastric adenocarcinoma growth is mediated through cyclin D1. American Journal of Physiology. Gastrointestinal \& Liver Physiology, 2003, 285(1):G217-G222.

25. Smith AM, Watson SA. Gastrin and gastrin receptor activation: an early event in the adenoma-carcinoma sequence. Gut, 2000, 47(6):820-824.

26. Liu $Y$ et al. Gastrin (G) cells and somatostatin (D) cells in patients with dyspeptic symptoms: Helicobacter pylori associated and non-associated gastritis. Journal of Clinical Pathology, 2005, 58(9):927-931.

27. Ferrand A, Wang TC. Gastrin and cancer: a review. Cancer Letters, 2006, 238(1):15-29.

28. Maciorkowska E et al. Mucosal gastrin cells and serum gastrin levels in children with Helicobacter pylori infection. Advances in Medical Sciences, 2006, 51:137-141.
29. Väänänen $\mathrm{H}$ et al. Non-endoscopic diagnosis of atrophic gastritis with a blood test. Correlation between gastric histology and serum levels of gastrin-17 and pepsinogen I: a multicentre study. European Journal of Gastroenterology \& Hepatology, 2003, 15(8):885-891.

30. Konturek PC et al. Helicobacter pylori, gastrin and cyclooxygenases in gastric cancer. Journal of Physiology \& Pharmacology, 2000, 51:737-749.

31. Konturek PC et al. Influence of gastrin on the expression of cyclooxygenase-2, hepatocyte growth factor and apoptosisrelated proteins in gastric epithelial cells. Journal of Physiology \& Pharmacology, 2003, 54(1):17-32.

32. Yamagata $\mathrm{R}$ et al. Cyclooxygebase-2 expression is increased in early intestinal-type gastric cancer and gastric mucosa with intestinal metaplasia. European Journal of Gastroenterology \& Hepatology, 2002, 14(4):359-363.

33. Chan AO et al. Promoter methylation of E-cadherin gene in gastric mucosa associated with Helicobacter pylori infection and in gastric cancer. Gut, 2003, 52(4):502-506.

34. Chan AO. E-cadherin in gastric cancer. World Journal of Gastroenterology, 2006, 12(2):199-203.

35. Milne AN et al. Early-onset gastric cancers have a different molecular expression profile than conventional gastric cancers. Modern Pathology, 2006, 19(4):564-572.

36. Wijnhoven BP, Dinjens WN, Pignatelli M. E-cadherin-catenin cell-cell adhesion complex and human cancer. British Journal of Surgery, 2000, 87(8):992-1005.

\section{Infectious agents and cancer}

Infectious agents are responsible for almost $22 \%$ of cancer deaths in the developing world and $6 \%$ in industrialized countries. Viral hepatitis B and C cause cancer of the liver; human papilloma virus infection causes cervical cancer; the bacterium Helicobacter pylori increases the risk of stomach cancer. In some countries the parasitic infection schistosomiasis increases the risk of bladder cancer and in other countries the liver fluke increases the risk of cholangiocarcinoma of the bile ducts. Preventive measures include vaccination and prevention of infection and infestation.

Further information about WHO's response to cancer can be found at: http:/ / www.who.int/cancer/en/ 